\title{
A research agenda for public administration and public sector management
}

\author{
Andrew Massey
}

Primum non nocere.

\section{Why have a new research agenda?}

The study of human history teaches us that much of life is analogous to a palimpsest. The original aims and older versions of political and administrative systems remain, but are constantly overlain by new ideas and novel approaches (see for example, Cunliffe, 2017). Old ideologies wither to be replaced by contemporary creeds, our understanding of them either aided or distorted by the methodologies deployed in science and social science; there are few eternal verities, but much that is recycled. The technological revolutions of recent generations produce immense amounts of data and new knowledge and this in turn drives social and political change. It has been this way in human society for millennia; it is the human condition. For example, the domestication of horses on the Pontic-Caspian steppe (modern Kazakhstan) sometime in the fourth or fifth millennia BC allowed the development of pastoralism to accelerate; thereafter population growth led to the evolution of early political systems (Cunliffe, 2017). Then came the development of militia and of cavalry, and from this vast armies of conquest (Cunliffe, 2017, 76; 469-70). These exported religions, technologies and political structures. There was both mimetic and coercive isomorphism across societies and cultures. They also evolved and exported the concept of the state and of administration. As Herson (1957/2013, 61) noted in relation to ancient Imperial China:

The society in which the Imperial civil service operated was a mixture of governmental absolutism and freedom from restraint. In principle, the government and hence society, was built upon a system of absolute rule, with an emperor at its head and a civil service as the chief instrument of that rule.

It was to be a global pattern, the civil service was formed as an instrument of the ruler, its purpose to collect taxes and enforce the will of the king or emperor. It was a pattern only effectively challenged from the time of the English civil war in the seventeenth century and the establishment of the American Republic with its 
insistence, based on English Liberal Theory, on the limits to government and the need for accountability (see for example, Bevir, 2013).

Not all transference, therefore, is universally 'good'. For example, in the fifth century $\mathrm{BC}$ Herodotus, in describing the burial of a Scythian king, observed the slaying and co-burial of his favourite concubine, cook, groom, horses and 50 young attendants, along with food, weapons, carriages and all manner of implements the king would need in the afterlife (Cunliffe, 2017, 224-6). These practices were emulated by other societies, but were themselves probably examples of mimesis. Although abhorrent to modern sensitivities, this was the politically correct procedure of the day and reflected the transmission of a complex mix of beliefs and political processes along the Silk Road. These displaced, impacted and evolved with earlier cultures; a thesis, antithesis and synthesis that continues in modern globalised societies. It is a process of change that is once again being tracked along the new Silk Road and elsewhere. In public administration, the dominant Anglo-American and Continental Western European paradigms are being challenged by rising powers and the latent inheritance of more ancient cultures (Drechsler, 2015). Vestigial and contemporary approaches to administering the public sector are fusing together and during their delivery utilising new technologies in a way that challenges our understanding of what public administration is there for. Modern developments even invite queries regarding the very notion of 'good governance'. An appreciation of the context of human activity is essential if it is to be truly understood, as is the deployment of the most efficacious methodology that allows researchers to understand both the phenomena being studied and the full context of their location. It may be observed that humans are both inquisitive and acquisitive and research underpins both endeavours. Indeed, 'there are many reasons to conduct research and there are many different types of research, but it is not often (or often enough) that we ask the Socratic question: Why do we do this thing?' (Massey, 2016, 75-6). The perspective adopted for this book is that the:

relentless transformation of public sector institutions and practices globally presents managers with a conundrum. The determination to make government transparent, efficient and accountable through improving audit, reporting and evaluation using measurable indicators of success often leads to a variety of unintended consequences. (Massey, 2017, 457-8)

As a part of the series of books, Elgar Research Agendas, this volume is devoted to addressing significant issues that are current in the Public Administration (PA) research field and attempting to predict future trends. It builds on current research and theory to suggest where future research may or indeed ought to be focused. In advocating the future directions for the development of research, this book is divided into chapters that have overlapping theoretical, thematic and geographical perspectives.

As a discipline, PA has always been concerned with impact. Impact in the conscious application of applying research in resolutely seeking to solve real world problems. 
In using this logic, therefore, PA is a discipline that by its very nature is and must continue to be multidisciplinary. As such, PA is a paradox; in order to be an effective, applicable, 'useful' discipline, PA has to be multidisciplinary. We understand the world via theoretical frameworks, but these in turn must be grounded in empirical reality. To that end, this book strives to secure some signposts towards the future direction of the discipline. A caution issued by Pollitt is apposite at this point. He aimed:

to say something about the field of scholarship in which I have spent three quarters of my adult working life. My belief is that, in parts of Europe at least, it is in some peril, and that we have a role to play. An EGPA survey and interview conceived by Geert Bouckaert was carried out 8 years ago and showed that a strong majority of PA scholars believed both in the scientific study of the subject AND in its values and ethic of improved services for citizens from respected, well-trained and remunerated public servants. As do I. Yet today, we face rising populism, nationalism and racism. The authority, expertise and impartiality of civil servants is under attack on all sides, but what we see in academic PA is too often a retreat into scholasticism or, at the other extreme, a kind of highbrow management consultancy. Of course we need both these types, but we also need a solid core of PA scholars who practice independent, high-quality critical analysis of big things which are happening now and will happen in future (climate change, demographic change, migration). Scholars who will build and find funding for ambitious projects aimed at those issues, simultaneously growing networks of concerned scholars across disciplines and fields. And - most importantly - who communicate, not only in learned journals, but also on websites and blogs, radio and TV and the press. Many citizens really are interested in why their schools are failing or their police are corrupt, and far less so in what celebrity politicians said to each other yesterday. We should be a respected voice addressed to that appetite. (Pollitt in Bouckaert and Massey, 2018)

In order to embrace this appeal for a responsive PA that addresses the intractable problems of society and seeks to do so within a framework of good governance, or at the very least to do no harm (to paraphrase the Hippocratic Oath), future research must be innovative, challenging and above all it must be brave. It needs to speak truth unto power and meet head on the wicked issues of the day, not the least of which is malfeasance by those who have assumed high office.

\section{Research relevance in public administration}

There have been many recent publications exploring the future of the discipline (for example, Diamond and Liddle, 2012; O'Leary et al., 2011). It has been argued that PA 'has a multiple personality partly because it comes from different places and partly because it is attempting to get to different destinations', it evolved out of law and political studies in the eighteenth and nineteenth centuries and more latterly organisation theory and other social science disciplines such as sociology, and anthropology (Pollitt, 2010, 292-4; Massey, 2018). What unifies PA as an identifiable focus is 'its subject - the state, the public sector, and the public realm 
- not its aims, theories or methods. It is, in effect, a community of interest' (Pollitt, 2010, 292). The problem is the community of interest can often become communities of interests and paradigm disputes emerge. PA and public policy journals continue to publish papers in the case study format, but they also publish papers that contain 'multiple regression analyses, attitude surveys, ethnographic studies', and this can lead to scholars working 'in their silos, with case study people talking to other case study people and number crunchers ditto', leading in the worst case to quantitative methodologists abusing the 'soft' case study people who 'would be scorned in their turn by the inconsequential but oh-so-sophisticated decentred, postmodern textualists' (Pollitt, 2010, 293). A positive future for PA research is to build on the growing trend to integrate all approaches into teams that also include a multidisciplinary dimension, increasingly across a range of institutions and countries (ibid.). To be relevant, the research needs to keep a focus on impact and on strategic issues as well as wicked issues.

But as is suggested in the foregoing section, the research also has to be presented in a way that is understandable beyond the small sub-discipline in which it is presented. Quantitative analyses need to be interpreted for non-quantitative researchers and political science needs to be accessible to other disciplines and vice versa. Johnston argues PA (and indeed academia generally) ought to take an Occam's razor approach. William Occam, a scholar in the late Middle Ages, criticised other scholars for interminable elaboration of theories and concepts, arguing they ought not to 'be multiplied beyond necessity' (Johnston, 2012, 1-24). In other words, contemporary researchers should be mindful to avoid gratuitous proliferation and defence of sub-disciplines. Developments in PA research ought to embrace a multi-theoretical and broad methodological approach in order to build on the benefits of interdisciplinarity, not fight paradigm wars. Needless elaborations and multiplication of sub-disciplines is a hindrance to understanding and not an aid; what is required is greater emphasis on breadth as well as depth. There are of course paradoxes in this approach. In the case of medicine the increase in knowledge has led to a rapid increase in sub-fields such that in advanced medicine there is rarely such a thing as a general physician or a general surgeon; there are experts in minor aspects of different parts of the human body (Raadschelders, $2011,34)$. Such specialisation allows a Fordist approach to medicine and surgery; experts in restricted fields (following five years of medical school and several further years of training) bring to bear a finely focused expertise on one component of the human form. But it leads to what Willis (a general practitioner) refers to as the paradox of progress (1995). So focused are the specialists that they often miss the benefits of assessing the whole person; indeed they will become steadily less able to appreciate the need to do so as they progress in their careers and will lose many of the skills they developed during the seven years of training. So it is also with the Fordist approach to social science. It is imperative to seek to simplify some areas of research that have become overcomplicated, to remember that 'whatever form or guise the discipline takes, it is the study of government, and this will continue' (Johnston, 2012, 2). 
One approach to this is to adopt an interpretive methodology to understanding what it is we are studying:

We often interpret our world through stories. This is as true of public administration and business as it is of other parts of our life. (Bevir and Rhodes, 2006 in Massey, 2018)

The need to simplify and interpret what we are doing in terms of understandable metaphors allows cognisance across boundaries and for practitioners beyond academe:

Less information delivers more understanding. Likewise, not only do societies understand themselves and their political systems through stories and myths, especially those that hark back to an heroic past, but individuals often refuse to believe empirically derived facts and data that complicate and contradict their view of the world, their false understanding of their own consciousness, which allows them to chart their way through life. (Massey, 2018)

False understanding leads to false news and a wilful refusal to accept evidencebased policies (Flynn et al., 2017).

This book provides chapters by active researchers that suggest the way research can be conducted and its products delivered in the future. They are contributing to the debate, but doing so in a methodologically eclectic manner and expressing a concern to evolve the discipline in ways which serve the understanding of knowledge and deliver a useful body of evidence to policy practitioners; they seek better governance from governments. We begin with Rod Rhodes (Chapter 2) and a restatement of his call for combining an interpretive approach with ethnographic methods in PA. It reiterates his concern that although there is a place for positivist methodologies they can only tell us part of what we need to know and that an interpretive approach allows an explanation of the role of networks and the interconnections between individuals. The chapter attempts to explain the importance of tradition, history and inherited theories as a way people come to believe the things they do and the way in which they understand the social and political world they inhabit. Although not opposing quantitative methodology and the use of big data, the interpretive and ethnographic approaches are firmly within the qualitative data camp. Rhodes then works through five case studies to illustrate the efficacy of these approaches to aid understanding of the role of public sector managers and also the way in which the policy process and policy networks actually work.

In Chapter 3, Christopher Pollitt discusses what he refers to as 'shadowland', the poorly mapped and murky arena between PA research and practice. He does this partly to make clear that in his opinion PA research is for practice and that most students of PA will not become academics, but they will engage in practice. Pollitt discusses six ways in which PA academics can assist practitioners and gives examples, but is careful to note there are overlaps and that the notion of impact is often vague and ill-defined. He calls for research to be more focused on wicked issues 
and in particular those issues that are going to bedevil future generations; climate change, demographic change, technological change and austerity, identifying a paucity of engagement with these topics in published PA literature compared to other disciplines. David Walker asks in Chapter 4 how PA can frame questions in such a way as to deliver useful answers for policymakers and practitioners. He notes the absurdities of 'weaponising' the research impact agenda and asks pertinent questions as to how it can reasonably be measured and if so the validity of those measurements. He argues that over the past four decades there has been a constant reform agenda by successive prime ministers and government parties to reduce and control 'the state'. Given the propensity of policymakers to cherry-pick research he queries whether the academics' relationship with the state over this time has been subversive, supportive or indifferent, noting it ought to be the latter. There follows an erudite discussion as to the evidence for each of these with regard to PA, concluding there remains a need to locate PA research somewhere between solipsism and evidence, but that PA scholars need to give more 'satisfying accounts' of what public administrators do.

With Chapter 5 by Trui Steen, Taco Brandsen and Bram Verschuere, the book moves from epistemological reflections about the nature of PA, to a discussion of a current major theme in the discipline: co-production and social innovation. They describe PA as having taken a long march to new governance concepts via a series of small steps towards the edge of its comfort zone. They argue it brings PA into new, wilder territory and the discipline needs to collaborate much more with other disciplines, something that is itself a core theme of this book. Part of the reason for this is due to what they refer to as society being unleashed through new forms of delivering services via governance institutions: social innovation, co-production and co-governance. They work through these concepts and discuss what it means for PA research, concluding the need to be bold and assertive in developing new interdisciplinary techniques. Claire Dunlop, in Chapter 6, picks up on the impact of research theme and asks bluntly, is PA ready to be relevant? She rehearses the arguments in favour of and against the call for relevance and impact, noting the tendency of the powerful to simply ignore those findings with which they disagree, but then, as Walker argued in an earlier chapter, that is their prerogative, it is the academic prerogative to be indifferent. Perhaps PA scholars when they find theory evidence and advice ignored would do well to adopt the refrain of the character Rudolf Abel in the film Bridge of Spies, when asked if he was worried, replies, 'Would it help?' In a sense that simple question lies at the heart of Dunlop's chapter (and indeed that of several others) when we offer up our evidence and our opinions to policymakers, do they help and if they do and we are still ignored does it make a difference? Dunlop debates the relevance of the research of PA scholars and the tensions and dilemmas of trying to make an impact. She relates this to the impact case studies of the last Research Excellence Framework in the UK and asks, how did we do? It is probably too early to tell.

Claire Dunlop teams up with Claudio Radaelli in Chapter 7 to explore a theme at the heart of PA, but somewhat under-researched: regulation and corruption. 
They provide a fairly uncontested definition of corruption, before arguing that any form of government intervention, including regulation, creates opportunities for corruption; it is an 'empirical manifestation of the trade-off between market failure and government failure'. Dunlop and Radaelli work through the different perspectives in the literature, paying attention to the amount of regulation and the type of government intervention, and the use of various policy instruments. They conclude that for future research, PA needs to pay more attention to the policy instruments used by different governments and to set these within the broader context of the whole (local) policy mix.

A magisterial review and analysis of East Asian PA in China, Japan and the Republic of South Korea is delivered by Pan Suk Kim in Chapter 8. Kim explores both the indigenous historical influence on modern Asian PA and the impact of US, UK and German influences, outlining the modern fusion in each of the countries that have a rich combination of ancient and ultra-modern dynamics. Kim notes that China is the world's second largest economy, Japan is the third largest and Korea is the eleventh; he argues that PA has played a pivotal role in this and that its global impact is destined to increase too. The East Asian model, or models, is based upon the structuring of a strong administrative state. He cites analysis that argues in East Asia there are 'several favourable preconditions of a broader socio-economic and political nature, such as a relatively homogenous population, high levels of human capital formation, competent bureaucracies, and fairly authoritarian governments'. A key challenge within all three countries, given their history and political structures, is to foster excellence in PA practice, education and research, and this will need to include issues such as state authority, legitimacy and governability. Chapter 9 remains in East Asia with Lan Zhiyong's perspective on the research agenda for $\mathrm{PA}$ in China under the Xi 'New Era', also known as the 'Xi Jinping New Era'. The Chinese government and PA scholars delineate this as a new age following on from the age of 'standing up' (1921-78), the age of 'better off' (1978-2018) which built the economy and China's modern state structures, through to the 'New Era' which will address the problems of environmental degradation, imbalanced development and develop a modern high-quality life for the citizens with China shouldering global responsibility. PA and public sector managers are core to this ambition. Lan's chapter analyses China's position from the perspective of the Thucydides trap, the Tacitus trap, the Middle-income trap, the Kindleberger trap, the Rousseau trap and the Gramsci trap. Lan argues that PA research needs to address these challenging problems.

Chapter 10, authored by Mark Evans, Patrick Dunleavy, Carmel McGregor and Max Halupka, applies the Australian experience to digital era governance. The chapter is based on original research including in-depth interviews with digital change thought leaders, exploring the shift, or rather intended shift, towards the establishment of digital era governance in the Australian public service. The chapter analyses the background and context of digital era change as well as the drivers to change, such as the Turnbull effect, the impetus to technological innovation and digitalisation of PA given by the former Prime Minister. It then examines 
the barriers to change, including cultural barriers, legislative barriers and resource barriers, which provides a nice link back to the previous chapters, especially those of Rhodes and Pollitt. Chapter 11 by Tiina Randma-Liiv and Külli Sarapuu turns towards the issues and challenges faced by small states in terms of public governance and PA. It is interesting to turn to the exploration of the issues with regard to small states at this juncture, given previous chapters have focused on large states, as Randma-Liiv and Sarapuu argue, much attention is applied to large states, but as a distinct field, research into small states is underdeveloped. They note, however, that 'small' is often a contested concept and definitionially there are a number of issues to overcome, and these they address whilst making the pertinent point that small countries are not smaller versions of larger countries. These differences are not simply quantitative, but also qualitative, as in 'most cases, human, financial and material resources in small states are limited' as compared to larger countries. In terms of PA research, they suggest that many issues in contemporary governance ought to be studied specifically from a small state perspective, that the issue of democracy in small states is also quite distinct in many practical and procedural ways, and specific issues of PA are also different in that there are often limits to specialisation and multifunctionality. Finally, small states research can give insights into governance per se, we need to link the study of small states to the broader theoretical and policy questions and this also presents interesting methodological challenges. The chapter also highlights the impact of geography, culture and context on PA and state architectures.

In Chapter 12 Sabine Kuhlmann provides an overview of the significant research issues in comparative PA and suggests future themes and topics. Her focus is on four areas of academic interest over the last few years; the context of reform for the administrative systems and conditions, public sector reforms, civil service systems and the politicisation of the public sector, and multilevel government including local government. She leads us through the different academic and theoretical approaches adopted to study each of these areas, delivering a formidable analysis of the literature and locating the work and the approaches within their context. She then suggests where future research should lie in terms of topics and methodologies and in some cases theoretical models in order to advance understanding in these sub-fields of PA. For anyone who is eager to understand the literature and salient issues across this wide area of comparative PA, this chapter provides an authoritative immersion in the subject. Gene Brewer uses Chapter 13 to tackle the often-contested topic of public service motivation. Brewer adopts the stance that the critics of the 'cottage industry' of public service motivation are the equivalent of 'canaries in the coal mine' and he takes us through the concerns with the topic: the validity of the concept per se and the scientific integrity of the approaches used to study it. Brewer assesses the theory and research on public service motivation, arguing that 'despite its enormous promise, theory and research on public service motivation is plagued by several nagging problems'. These include the question whether public service motivation is real or imagined; the normative nature of public service motivation; the conflation of public service with public sector leading to a confusion about what is actually meant by public service motivation. He 
suggests further research to explore and make clear the difference between selfinterest and public service motivation; explore the dark side of this motivation, the kind of service to higher causes, leading to deviant or even criminal behaviour; a reiteration of the difference between public service and the public sector. Brewer, therefore, touches on a theme of the book, the proliferation of sub-disciplines and the Fordism of the discipline.

The book concludes with a questioning and provocative chapter by Wolfgang Drechsler. He begins by critiquing current US (and Dutch) PA scholarship and journal publishing for being narrow, indeed parochial, and asserting a 'one, holy, Catholic and apostolic church' positivistic approach to the study of the discipline. He argues that 'the focus of PA today is gaming the real idea of PA as a scholarly discipline or area, is focusing at best on producing shadows at the wall of the cave, so that contents - one could argue - summarily falls to the side'. This is similar to political science and economics, he argues, but in those subjects, it does not matter as they have only a tenuous relationship to reality. In PA, however, it does matter as the purpose of research in PA is to connect theory and practice; to be useful. The problem, he argues, is that the application of method has become the point, not the tool, privileging form over content. He calls for a recognition of methodological and cognitive diversity, especially in regard to non-Western PA and the resurrection of the study and development of PA philosophy. After all, he ponders, if we cannot do things differently to machines then his apocryphal Dutch professor could write papers using a computer algorithm; perhaps some already do. In conclusion, what this book does is to bring together the observations, analysis and concerns of leading PA scholars from a range of perspectives and many different countries. There are a series of linking themes through the different chapters that clarify, focus and contribute to the research agenda for PA and public sector management. The book endorses the need for:

1. Relevance in the research in the field. If PA is not relevant then it is pointless, and to be relevant it has to engage with real world wicked issues and contribute to solving or at least ameliorating them.

2. PA to have impact as a core element in its striving to be relevant. By this it is meant that the discipline needs to join with other groups of researchers and address areas of concern where it has been underrepresented. For example, sustainability and climate change, disease control (think preventing the spread of Ebola) and issues around mass migration and inequality.

3. Theory must be related to practice and as was pointed out directly in several places in the book, if the practice (the reality) does not fit the theory then it is the theory that needs changing; PA may be related to economics and political science, but it is only connected to those parts that have real world impact.

4. PA research has to be methodologically promiscuous and shun a purist approach. A quantitative or qualitative methodological purity may bring with it warm feelings of virtue and superiority in those who practise them, but it is not the way to understand what Price referred to as the 'seamy side of politics', by which he meant an understanding of how countries actually work (1983). 
In the process of actioning new research, colleagues need to remember that knowledge is there to be used to hold agencies of governance to account, not just as an input into accounting and audit. Audit and accounting are key aspects to accountability, but they are only aspects, one of the great disservices that new public management has rendered upon public sector management is to peddle the belief that accountability through accountancy is key to controlling public policy implementation and evaluation, when it can only ever be one aspect of understanding the role and function of PA and governance. The pursuit of new knowledge in a variety of ways (for example, big data, the digital economy, ethnography, public service motivation, joining with sociology, anthropology, medical researchers, and so on) is to provide an evidence base to deliver effective and preferably economic public service and also to address wicked policy problems. Humanity is at root acquisitive and inquisitive (Cunliffe, 2017), and effective PA research can ensure a contribution towards making those elements work for the common good.

\section{References}

Bevir, M. (2013), A Theory of Governance, Berkeley, CA: University of California Press.

Bevir, M. and Rhodes, R.A.W. (2006), Governance Stories, London: Routledge.

Bouckaert, G. and Massey, A. (2018), 'In memoriam of Christopher Pollitt', International Review of Administrative Sciences, 84 (3), 427-9.

Cunliffe, B. (2017), By Steppe, Desert and Ocean: The Birth of Eurasia, Oxford: Oxford University Press.

Diamond, J. and Liddle, J. (2012), Emerging and Potential Trends in Public Management: An Age of Austerity, Bingley, UK: Emerald Publishing.

Drechsler, W. (2015), 'Paradigms of non-Western public administration and governance', in Massey, A. and Johnston Miller, K. (eds), The International Handbook of Public Administration and Governance, Cheltenham, UK and Northampton, MA: Edward Elgar, pp. 104-31.

Flynn, D.J., Nyhan, B. and Reifler, J. (2017), 'The nature and origins of misperceptions: understanding false and unsupported beliefs about politics', Political Psychology, 38 (S1), 127-50.

Herson, L. (1957), 'China's imperial bureaucracy: its direction and control', Public Administration Review, 17 (1), 44-53, reprinted in Massey, A. (2013), Public Sector Reform, vol. I, London: Sage, pp. 149-63.

Johnston, K. (2012), 'The future of the discipline: trends in public sector management', in Diamond, J. and Liddle, J. (eds), Emerging and Potential Trends in Public Management: An Age of Austerity, Bingley, UK: Emerald Publishing, pp. 1-24.

Massey, A. (2016), 'Editorial: PMM has a real-world impact', Public Money and Management, 36 (2), 75-6.

Massey, A. (2017), 'Editorial: public service - global issues, local suggestions', Public Money and Management, 37 (7), 457-8.

Massey, A. (2018), 'Persistent public management reform: an egregore of liberal authoritarianism', Public Money and Management, online version available at: https://doi.org/10.1080/09540962.2018.1448160.

Massey, A. and Johnston, K. (eds) (2015), The International Handbook of Public Administration and Governance, Cheltenham, UK and Northampton, MA, USA: Edward Elgar Publishing, pp. 104-32.

O'Leary, R., Van Slyke, D.M. and Kim, S. (2011), The Future of Public Administration Around the World: The Minnowbrook Perspective, Washington, DC: Georgetown University Press.

Pollitt, C. (2010), 'Envisioning public administration as a scholarly field in 2020', Public Administration Review, 7o, special issue, December, S292-4. 
Price, D.K. (1983), America's Unwritten Constitution, Baton Rouge, LA: Louisiana State University Press. Raadschelders, J. (2011), Public Administration: The Interdisciplinary Study of Government, Oxford: Oxford University Press.

Willis, J. (1995), The Paradox of Progress, Oxford: Radcliffe Medical Press. 